University of Nebraska - Lincoln

DigitalCommons@University of Nebraska - Lincoln

4-18-2019

\title{
Clinico-Neuropathological Findings in the Oldest Old from the Georgia Centenarian Study
}

Jirayu Tanprasertsuk

Tufts University

Elizabeth J. Johnson

Tufts University

Mary Ann Johnson

Tufts University

Leonard W. Poon

University of Georgia

Peter T. Nelson

University of Kentucky

See next page for additional authors

Follow this and additional works at: https://digitalcommons.unl.edu/usdaarsfacpub

Tanprasertsuk, Jirayu; Johnson, Elizabeth J.; Johnson, Mary Ann; Poon, Leonard W.; Nelson, Peter T.; Davey, Adam; Martin, Peter; Barbey, Aron K.; Barger, Kathryn; Wang, Xiang-Dong; and Scott, Tammy M., "Clinico-Neuropathological Findings in the Oldest Old from the Georgia Centenarian Study" (2019). Publications from USDA-ARS / UNL Faculty. 2185.

https://digitalcommons.unl.edu/usdaarsfacpub/2185

This Article is brought to you for free and open access by the U.S. Department of Agriculture: Agricultural Research Service, Lincoln, Nebraska at DigitalCommons@University of Nebraska - Lincoln. It has been accepted for inclusion in Publications from USDA-ARS / UNL Faculty by an authorized administrator of DigitalCommons@University of Nebraska - Lincoln. 


\section{Authors}

Jirayu Tanprasertsuk, Elizabeth J. Johnson, Mary Ann Johnson, Leonard W. Poon, Peter T. Nelson, Adam Davey, Peter Martin, Aron K. Barbey, Kathryn Barger, Xiang-Dong Wang, and Tammy M. Scott 


\title{
Clinico-Neuropathological Findings in the Oldest Old from the Georgia Centenarian Study
}

\author{
Jirayu Tanprasertsuk ${ }^{\mathrm{a}, \mathrm{b}}$, Elizabeth J. Johnson ${ }^{\mathrm{b}}$, Mary Ann Johnson ${ }^{\mathrm{c}}$, Leonard W. Poon ${ }^{\mathrm{d}}$, \\ Peter T. Nelson ${ }^{\mathrm{e}}$, Adam Davey ${ }^{\mathrm{f}}$, Peter Martin ${ }^{\mathrm{g}}$, Aron K. Barbey ${ }^{\mathrm{h}}$, Kathryn Barger ${ }^{\mathrm{b}}$, \\ Xiang-Dong Wang ${ }^{\mathrm{b}}$ and Tammy M. Scott ${ }^{\mathrm{a}, *}$ \\ ${ }^{\mathrm{a}}$ Gerald J. and Dorothy R. Friedman School of Nutrition Science and Policy, Tufts University, Boston, MA, USA \\ ${ }^{\mathrm{b}}$ Jean Mayer USDA Human Nutrition Research Center on Aging at Tufts University, Boston, MA, USA \\ ${ }^{\mathrm{c}}$ Department of Nutrition and Health Sciences, University of Nebraska Lincoln, Lincoln, NE, USA \\ ${ }^{\mathrm{d}}$ Institute of Gerontology, University of Georgia, Athens, GA, USA \\ ${ }^{\mathrm{e}}$ Department of Pathology, Division of Neuropathology, University of Kentucky, Lexington, KY, USA \\ ${ }^{\mathrm{f}}$ Department of Behavioral Health and Nutrition, University of Delaware, Newark, DE, USA \\ ${ }^{\mathrm{g}}$ Human Development \& Family Studies, Iowa State University, Ames, IA, USA \\ ${ }^{\mathrm{h}}$ Beckman Institute for Advanced Science and Technology, University of Illinois at Urbana-Champaign, \\ Urbana, IL, USA
}

Handling Associate Editor: Sid O’Bryant

Accepted 18 April 2019

\begin{abstract}
.
Background: Centenarian studies are important sources for understanding of factors that contribute to longevity and healthy aging. Clinico-neuropathological finding is a key in identifying pathology and factors contributing to age-related cognitive decline and dementia in the oldest old.

Objective: To characterize the cross-sectional relationship between neuropathologies and measures of premortem cognitive performance in centenarians.

Methods: Data were acquired from 49 centenarians ( $\geq 98$ years) from the Georgia Centenarian Study. Cognitive assessment from the time point closest to mortality was used ( $<1$ year for all subjects) and scores for cognitive domains were established. Neuropathologies [cerebral atrophy, ventricular dilation, atherosclerosis, cerebral amyloid angiopathy (CAA), Lewy bodies, hippocampal sclerosis (HS), hippocampal TDP-43 proteinopathy, neuritic plaque (NP) and neurofibrillary tangle (NFT) counts, Braak staging, and National Institute on Aging-Reagan Institute (NIARI) criteria for the neuropathological diagnosis of Alzheimer's disease (AD)] were compared among subjects with different ratings of dementia. Linear regression was applied to evaluate the association between cognitive domain scores and neuropathologies.

Results: Wide ranges of AD-type neuropathological changes were observed in both non-demented and demented subjects. Neocortical NFT and Braak staging were related to clinical dementia rating. Neocortical NFT and NP, Braak and NIARI staging, cerebral and ventricular atrophy, HS, CAA, and TDP-43 proteinopathy were differentially associated with poor performance in multiple cognitive domains and activities of daily living.

Conclusion: AD-type pathology was associated with severe dementia and poor cognition but was not the only variable that explained cognitive impairment, indicating the complexity and heterogeneity of pathophysiology of dementia in the oldest old.
\end{abstract}

Keywords: Alzheimer's disease, amyloid plaques, centenarians, cognition, neurofibrillary tangles, neuropathology

\footnotetext{
${ }^{*}$ Correspondence to: Tammy M. Scott, PhD, Gerald J. and Dorothy R. Friedman School of Nutrition Science and Policy, Tufts
}

University, 75 Kneeland Street, Boston, MA 02111, USA. Tel.: +1 617636 3544; E-mail: Tammy.Scott@tufts.edu. 


\section{INTRODUCTION}

Centenarians are a unique demographic and are the fastest-growing age group in many developed nations. The number of centenarians is predicted to reach 25 million worldwide by 2100 [1]. Centenarian studies are important sources for our understanding of genetics and modifiable factors that contribute to longevity and healthy aging [2]. Because advanced age is the number one risk factor of late-onset Alzheimer's disease (AD), the most common form of dementia, it was originally assumed that dementia is a natural process of aging [3]. However, studies in the oldest old ( $\geq 90$ years old) have shown that cognitive status varied drastically from person to person toward the end of life, implying that dementia is not an inevitable symptom even in those living beyond the expected human lifespan [4, 5]. Given that the world population is shifting toward older ages, and currently there is no treatment for $\mathrm{AD}$ and other forms of dementia, there is an urgency to identify characteristics associated with lower risk of dementia and its pathology.

Appreciation in cognitive findings from centenarian studies have been increasing in recent years [2]. Prevalence and incidence of dementia and agerelated cognitive impairment have been extensively described in many centenarian studies worldwide [5]. On the other hand, our current understanding of clinico-pathological (CP) correlation with dementia in centenarians is extremely limited. Existing evidences suggest distinctive $\mathrm{CP}$ pattern from those of less advanced age [6,7]. Neuritic plaque (NP) and neurofibrillary tangle (NFT) are two classical neuropathological hallmarks of $\mathrm{AD}$ [8]. NP, also known as senile plaque, is an extracellular aggregation of amyloid- $\beta(A \beta)$ peptide that forms a dense core surrounded by degenerative neurites. NFT is an intracellular aggregate of hyperphosphorylated tau protein. Existing neuropathological studies in the oldest old often performed only a crude assessment of premortem cognitive status [9-15]. The Georgia Centenarian Study (GCS), the longest-running centenarian study in the US, offers a unique dataset that encompasses extensive premortem neuropsychological and postmortem neuropathological assessments in centenarians with varied degree of cognitive status, as well as variables that may confound the CP association (such as gender, race, education, and chronic illness) [16]. Prevalence of dementia, cognitive functioning, and neuropathological assessment in the GCS centenarians have been separately described
[17-19]. This report is the first comprehensive CP characterization in the GCS.

The main objective for this present analysis was to characterize the cross-sectional relationship between neuropathological variables and both subjective and objective measures of premortem cognitive performance in centenarians from the GCS. Previous CP studies often combined centenarians with younger old adults ( $<90$ years old), but findings from these studies raised questions regarding the confounding effect from longevity-associated characteristics of the oldest old [20-23]. There have been limited reports on $\mathrm{CP}$ correlations exclusively in 40 centenarians from the 100-Plus Study of Dutch centenarians who were all cognitively intact at the enrollment [24], 14 centenarians from the New England Centenarian Study (NECS) [25], and others with very limited numbers of subjects [9-11, 26-28]. Findings from the GCS will expand our understanding of $\mathrm{CP}$ correlation as it is one of the keys to identify pathology and factors contributing to the prevention or delay of age-related cognitive decline and, distinctively in centenarians, successful aging.

\section{METHODS}

\section{Subject recruitment}

Forty-nine subjects included in this study were a subset of centenarians (defined as $\geq 98$ years old) enrolled in the GCS. The protocol of the GCS has been described in detail [16, 29]. Briefly, phase III of the GCS was a population-based multidisciplinary study conducted in 44 counties in northern Georgia between 2001 and 2007. The aim of the GCS is to identify biological, psychological, and social factors contributing to survivorship and successful aging. All protocols were performed with an approval from the University of Georgia Institutional Review Board. Separate approval for using de-identified data for the present analyses was obtained from the Tufts University/Tufts Medical Center Institutional Review Board.

\section{Cognitive assessment and cognitive domain composite scoring}

Cognitive assessment was performed at baseline and every 6 months until mortality after the enrollment at subject's residence as previously described [29]. Only subjects who had cognitive assessment within 1 year of mortality were used for these 
analyses. Dementia status was assessed by geriatric psychiatrists using Global Deterioration Scale (GDS) and subjects were grouped based on GDS score. A score of 1-2 on GDS were clinically defined as no dementia; a score of 3 represented mild cognitive impairment; and a score of 4-7 represented increasing severity of dementia from mild to severe [30]. Objective measures of cognition were performed using different cognitive tests previously described $[18,31]$. Cognitive tests included Mini-Mental State Examination (MMSE), Severe Impairment Battery (SIB), Fuld Object Memory Evaluation (FOME), Controlled Oral Word Association Test (COWAT), Wechsler Adult Intelligence Scale Third Edition (WAIS-III) Similarities, Behavioral Dyscontrol Scale (BDS), and the Consortium to Establish a Registry for Alzheimer's Disease (CERAD) battery which included Verbal Fluency (VF), Boston Naming Test (BNT), Constructional Praxis (CP), and Word List Memory Test (WLMT). Depression was assessed using Geriatric Depression Scale Short Form (GDSSF), and activities of daily living were assessed using Direct Assessment of Function Status (DAFS). Scores from each test were normalized using z-scoring among all subjects. Adapted from Bowman et al. [32], composite scores for five cognitive domains (memory, executive function, language, visuospatial function, attention/encoding), depression, and activities of daily living were calculated by averaging the $z$-scores of cognitive tests (Supplementary Table 1). Global cognition composite scores were also derived by combining total cognitive testing z-scores. Only cognitive tests from the time point closest to death were used to calculate cognitive domain composite scores. Missing test scores were excluded, and the denominator changed accordingly for the calculation of composite scores.

\section{Brain collection and assessment for neuropathology}

Brain tissues were collected at autopsy at the University of Georgia-Athens and delivered to the University of Kentucky Alzheimer's Disease Center (UK-ADC) for neuropathological assessment as previously described [19]. Assessment of neuropathology included cerebral atrophy, ventricular dilation, cerebral atherosclerosis, cerebral amyloid angiopathy (CAA), Lewy body pathology (LBP), hippocampal TAR DNA binding protein 43 (TDP43) pathology, hippocampal sclerosis (HS), infarcts, averaged NP and NFT counts, Braak and Braak staging (hereafter referred to as Braak staging), and National Institute on Aging-Reagan Institute (NIARI) criteria for the neuropathological diagnosis of AD. Cerebral atrophy and ventricular dilation are measures of neuronal loss [33]. Cerebral atrophy was graded from absent, mild, moderate, to severe. Ventricular dilation was assessed as absent or present. Cerebral atherosclerosis and CAA, which is a deposition of $A \beta$ in the wall of blood vessels, are markers of cerebrovascular disease [8]. Cerebral atherosclerosis and CAA were graded from absent, mild, moderate, to severe. LBP were evaluated according to the consensus-based evaluation [34, 35]. Aberrant TDP-43 immunohistochemistry refers to staining that is cytoplasmic, neuritic, or tangle like (TDP-43 is normally localized to the nucleus). Severity of hippocampal TDP-43 pathology was graded semi-quantitatively from absent, mild, moderate, and severe as previously described [36]. The neuropathological criterion for HS was selective neuronal loss and gliosis of hippocampus (Hip) section CA1 and subiculum (Sub), not readily ascribable to another pathology such as NFT or localizable infarction [37]. As previously described [19], NP and NFT counts were averaged from five microscopic fields that were most severely affected in each section from the following brain regions: frontal cortex (FC, Brodmann Area 9), temporal cortex (TC, Brodmann Areas 2122), parietal cortex (PC, Brodmann Areas 39-40), amygdala (Amy), entorhinal cortex (Ent), Hip section CA1, and Sub. Braak staging was employed as a global assessment of NFT progression as previously described [38]: Braak staging I-II (transentorhinal); Braak staging III-IV (limbic); Braak staging V-VI (neocortical). Braak staging I-II is characterized by a mild to moderate development of NFT and neuropil thread (NT) in the transentorhinal region. A modest number of NFT may be observed in the Hip section CA1. Isolated NFT may be scarcely observed in isocortical association areas including FC and TC. In Braak staging III-IV, both transentorhinal and Ent are severely affected by NFT and NT. Hippocampal CA1 also contains numerous NFT, as well as limbic structures (Amy, putamen, nucleus accumbens, thalamus). The Sub and isocortices in Braak staging III-IV remain only mildly affected by NFT. In Braak staging V-VI, transentorhinal, Ent, Hip, Sub, subcortical nuclei and isocortical cortices are severely affected by NFT or NT. NIARI AD neuropathology criteria summarize histological assessments of $A \beta$ deposits, staging of NFT (Braak staging), and scoring of NP 
into "no", "low", "intermediate", or "high" likelihood of $\mathrm{AD}[39]$.

\section{Statistical analysis}

Comparisons of subject characteristics and neuropathology among the four GDS groups were performed using Kruskal-Wallis rank sum test for continuous variables and Fisher exact test for categorical variables. Pairwise comparisons were further performed with Wilcoxon rank sum test. An association between neuropathological variables and cognitive domain scores was assessed using multiple linear regression adjusted for gender, race, education, hypertension, and diabetes. NP and NFT counts were $\log$ transformed in the regression models. $\mathrm{p}$ values were additionally adjusted using Benjamini \& Hochberg's false discovery rate (FDR) for multiple comparisons (R package 'stats'). All statistical anal- yses were performed in R 3.3.3. Significance level was set at $\alpha=0.05$ and FDR was reported.

\section{RESULTS}

\section{Subject characteristics}

Characteristics for 49 subjects analyzed in the present study are shown in Table 1 . All subjects were $\geq 98$ years old with an average of 102.2 years at death ( 8 cases were 98 or 99 years old at death). Most were females (90\%) and Caucasians (88\%). Fortyfive percent of subjects did not finish high school. On average, each subject took 7.9 medications, including antidepressant (29\%), antipsychotic (8\%), and antiinflammatory medications (10\%). Sixteen percent had diabetes while $51 \%$ had hypertension at death. Among those whose data for history of smoking and alcohol use were available $(67 \%$, most missing

Table 1

Subject Characteristics

\begin{tabular}{|c|c|c|c|c|c|c|}
\hline Characteristics & $\begin{array}{c}\text { All subjects } \\
(n=49)\end{array}$ & $\begin{array}{c}\text { GDS } 1-2 \\
(n=12)\end{array}$ & $\begin{array}{c}\text { GDS } 3 \\
(n=10)\end{array}$ & $\begin{array}{c}\text { GDS 4-5 } \\
(n=15)\end{array}$ & $\begin{array}{c}\text { GDS 6-7 } \\
(n=12)\end{array}$ & $p^{1}$ \\
\hline Age in years, mean (SD) & $102.2(2.5)$ & $101.5(2.0)$ & $102.6(2.1)$ & $102.7(3.3)$ & $101.8(2.5)$ & 0.583 \\
\hline Female, $n(\%)$ & $44(90 \%)$ & $9(75 \%)$ & $9(90 \%)$ & $14(93 \%)$ & $12(100 \%)$ & 0.251 \\
\hline Race, $n(\%)$ & & & & & & 0.046 \\
\hline Caucasian & $43(88 \%)$ & $12(100 \%)$ & $10(100 \%)$ & $13(87 \%)$ & $8(67 \%)$ & \\
\hline African American & $6(12 \%)$ & $0(0 \%)$ & $0(0 \%)$ & $2(13 \%)$ & $4(33 \%)$ & \\
\hline $\mathrm{BMI}$ in $\mathrm{kg} / \mathrm{m}^{2}$, mean $(\mathrm{SD})^{2}$ & $22.0(4.4)$ & $23.5(4.0)$ & $22.8(3.3)$ & $21.3(4.8)$ & $20.9(4.9)$ & 0.257 \\
\hline Education, $n(\%)$ & & & & & & 0.332 \\
\hline$<$ High school & $22(48 \%)$ & $4(33 \%)$ & $4(40 \%)$ & $7(50 \%)$ & $7(70 \%)$ & \\
\hline High school & $12(26 \%)$ & $4(33 \%)$ & $3(30 \%)$ & $2(14 \%)$ & $3(30 \%)$ & \\
\hline >High school & $12(26 \%)$ & $4(33 \%)$ & $3(30 \%)$ & $5(36 \%)$ & $0(0 \%)$ & \\
\hline No data & 3 & 0 & 0 & 1 & 2 & \\
\hline Number of medications, mean (SD) & $7.9(3.7)$ & $6.8(3.3)$ & $7.3(5.3)$ & $8.1(2.2)$ & $9.2(4.1)$ & 0.517 \\
\hline Antidepressant use, $n(\%)$ & $14(29 \%)$ & $2(17 \%)$ & $2(20 \%)$ & $5(33 \%)$ & $5(42 \%)$ & 0.511 \\
\hline Antipsychotic use, $n(\%)$ & $4(8 \%)$ & $0(0 \%)$ & $1(10 \%)$ & $2(13 \%)$ & $1(8 \%)$ & 0.827 \\
\hline Anti-inflammatory medication use, $n(\%)$ & $5(10 \%)$ & $1(8 \%)$ & $3(30 \%)$ & $0(0 \%)$ & $1(8 \%)$ & 0.100 \\
\hline Diabetes, $n(\%)$ & $8(16 \%)$ & $2(17 \%)$ & $0(0 \%)$ & $3(20 \%)$ & $3(25 \%)$ & 0.456 \\
\hline Hypertension, $n(\%)$ & $25(51 \%)$ & $8(67 \%)$ & $3(30 \%)$ & $7(47 \%)$ & $7(58 \%)$ & 0.371 \\
\hline Smoking, $n(\%)$ & & & & & & 0.712 \\
\hline Never & $28(85 \%)$ & $9(82 \%)$ & $8(89 \%)$ & $7(88 \%)$ & $4(80 \%)$ & \\
\hline Past & $4(12 \%)$ & $2(18 \%)$ & $1(11 \%)$ & $0(0 \%)$ & $1(20 \%)$ & \\
\hline Present & $1(3 \%)$ & $0(0 \%)$ & $0(0 \%)$ & $1(12 \%)$ & $0(0 \%)$ & \\
\hline No data & 16 & 1 & 1 & 7 & 7 & \\
\hline Alcohol use, $n(\%)$ & & & & & & 0.145 \\
\hline Never & $21(64 \%)$ & $4(36 \%)$ & $5(56 \%)$ & $7(88 \%)$ & $5(100 \%)$ & \\
\hline Past & $5(15 \%)$ & $4(36 \%)$ & $1(11 \%)$ & $0(0 \%)$ & $0(0 \%)$ & \\
\hline Present & $7(21 \%)$ & $3(27 \%)$ & $3(33 \%)$ & $1(12 \%)$ & $0(0 \%)$ & \\
\hline No data & 16 & 1 & 1 & 7 & 7 & \\
\hline$A P O E \varepsilon 4$ allele frequency ${ }^{3}$ & 0.09 & 0.04 & 0.10 & 0.12 & 0.11 & 0.167 \\
\hline
\end{tabular}

${ }^{1}$ Kruskal-Wallis test (continuous variables) and Fisher's exact test (categorical variables) was performed for comparisons among four groups. Comparisons for education, smoking, and alcohol were performed only with subjects whose data were available. ${ }^{2}$ One subject was a double amputee and BMI could not be calculated. ${ }^{3}$ The $\varepsilon 2$ or $\varepsilon 4$ allele frequency is the ratio of number of $\varepsilon 2$ or $\varepsilon 4$ allele to the total number of alleles (two per person) in each group. APOE genotype was not available in five subjects, two of whom had GDS 4-5 and three of whom had GDS 6-7. 
data were from demented subjects), most had no history of cigarette smoking or alcohol use. APOE $\varepsilon 4$ allele frequency was not significantly different among GDS groups. Subject characteristics were similar across GDS groups except the proportion of African Americans was significantly higher in advanced GDS groups.

The time interval between the cognitive assessment at the time point closest to death and the autopsy was less than one year for all subjects with a mean of $153 \pm 91$ days for those whose data could be accurately calculated (84\%). Availability of cognitive assessment data for each GDS classification is shown in Supplementary Table 2. As expected, MMSE and cognitive domain composite scores were significantly different among GDS groups as described in Supplementary Table 3. Composite scores were also highly correlated among cognitive domains as shown in Supplementary Table 4 . None of the subjects reported a history of clinical stroke.

\section{Neuropathology and dementia rating}

The neuropathology among centenarians is described in Table 2. Most subjects were absent of or had mild cerebral atrophy and ventricular dilation. All subjects who had moderate or severe cerebral atrophy scored $\geq 4$ on the GDS (presence of clinical dementia). Seven subjects with presence of ventricular dilation had some degree of cerebral atrophy and dementia. A trend between the presence of ventricular dilation and dementia status was observed $(p=0.065)$. All subjects had a certain degree of cerebral atherosclerosis. Forty-one percent were absent of amyloid angiopathy. Nine subjects (21\%) had LBP in at least one part of the brain-varying from the brain stem (3 subjects), limbic system (7 subjects), to neocortex (2 subjects). Certain degree of HS was present in at least one hemisphere in five subjects (11\%) not readily ascribable to another pathology in Hip. HS impeded the assessment of NP and NFT in Hip and Sub in three subjects. Proteinopathy of hippocampal TDP43 was also observed in 8 subjects $(32 \%)$ with its severity ranging from mild (20\%), moderate (10\%), to severe (2\%). Although HS and hippocampal TDP43 proteinopathy were not significantly associated with rating of dementia, it is worth pointing out that all subjects who were cognitively intact (GDS 1-2) were absent of these pathologies in Hip. Fifty-six percent of subjects whose data were available (24 out of 43 subjects) had at least one small infarct, but all were absent of medium to large infarcts.
Given the progression of NP and NFT across different AD stages [34,36], NP counts in higher brain structures (FC, TC, PC) and Amy were significantly greater than Ent, Hip, and Sub as expected in this cohort of subjects with varied degrees of cognition ( $p<0.001$ for all pair-wise comparisons). Meanwhile, NFT in Amy, Ent, Hip, and Sub was significantly higher than that in FC, TC, and PC ( $p<0.001$ for all pair-wise comparisons). Medians for NP and NFT counts were consistently lower than means in all brain regions, describing the high frequencies of subjects with NP and NFT counts lower than mean values (Figs. 1 and 2). It is also worth noting the comparable ranges of NP and NFT counts across GDS groups in many brain regions. NP counts were similar across GDS groups for all brain regions. In contrast, NFT counts in FC, TC, and Sub in GDS 6-7 were significantly higher than those in lower GDS groups $(p<0.05)$. Averaged NFT counts in PC in GDS 6-7 were also significantly higher than those in GDS $1-2$ and GDS $3(p<0.05)$. All subjects had some degree of NFT pathology, therefore none was in Braak staging 0 (no NFT pathology). A significantly higher proportion of subjects in Braak staging V-VI was also observed in advanced GDS groups $(p<0.05)$. Proportions of subjects in different NIARI AD neuropathology criteria were not statistically significant across GDS groups.

\section{Neuropathology and cognitive testing performance}

The associations between neuropathological variables and composite scores of global cognition, memory, executive function, visuospatial function, attention/encoding, depression, and activities of daily living, after adjusting for covariates-gender, race, education, hypertension, and diabetes are shown in Table 3. Variance explained for a composite score in each linear regression model (adjusted $\mathrm{R}^{2}$ ) is reported in Supplementary Table 5. Compared to those absent of cerebral atrophy, subjects with moderate or severe cerebral atrophy consistently performed worse in global cognition $(p<0.01, \mathrm{FDR}<0.05$ for moderate; $p<0.05$, FDR $<0.05$ for severe), memory $(p<0.01, \mathrm{FDR}<0.05$ for moderate; $p<0.05$, FDR $<0.05$ for severe), executive function $(p<0.01$, FDR $<0.05$ for moderate; $p<0.05$, FDR $<0.10$ for severe), language $(p<0.01, \mathrm{FDR}<0.05$ for moderate), visuospatial function $(p<0.05$, FDR $<0.05$ for moderate), and activities of daily living $(p<0.05$, FDR $<0.05$ for moderate and severe). Mild cerebral 
Table 2

Description of neuropathology 1

\begin{tabular}{|c|c|c|c|c|c|c|}
\hline Neuropathology & $\begin{array}{c}\text { All subjects } \\
(n=49)\end{array}$ & $\begin{array}{c}\text { GDS 1-2 } \\
(n=12)\end{array}$ & $\begin{array}{c}\text { GDS 3 } \\
(n=10)\end{array}$ & $\begin{array}{c}\text { GDS 4-5 } \\
(n=15)\end{array}$ & $\begin{array}{c}\text { GDS 6-7 } \\
(n=12)\end{array}$ & $p^{2}$ \\
\hline Cerebral atrophy, $n(\%)$ & & & & & & 0.229 \\
\hline Absent & $17(35 \%)$ & $7(58 \%)$ & $5(50 \%)$ & $3(20 \%)$ & $2(17 \%)$ & \\
\hline Mild & $25(51 \%)$ & $5(42 \%)$ & $5(50 \%)$ & $9(60 \%)$ & $6(50 \%)$ & \\
\hline Moderate & $4(8 \%)$ & $0(0 \%)$ & $0(0 \%)$ & $2(13 \%)$ & $2(17 \%)$ & \\
\hline Severe & $3(6 \%)$ & $0(0 \%)$ & $0(0 \%)$ & $1(7 \%)$ & $2(17 \%)$ & \\
\hline Ventricular dilation, $n(\%)$ & & & & & & 0.065 \\
\hline Absent & $42(86 \%)$ & $12(100 \%)$ & $10(100 \%)$ & $11(73 \%)$ & $9(75 \%)$ & \\
\hline Present & $7(14 \%)$ & $0(0 \%)$ & $0(0 \%)$ & $4(27 \%)$ & $3(25 \%)$ & \\
\hline Cerebral atherosclerosis, $n(\%)$ & & & & & & 0.236 \\
\hline Mild & $28(57 \%)$ & $9(75 \%)$ & $6(60 \%)$ & $9(60 \%)$ & $4(33 \%)$ & \\
\hline Moderate & $19(39 \%)$ & $2(17 \%)$ & $4(40 \%)$ & $6(40 \%)$ & $7(58 \%)$ & \\
\hline Severe & $2(4 \%)$ & $1(8 \%)$ & $0(0 \%)$ & $0(0 \%)$ & $1(8 \%)$ & \\
\hline Amyloid angiopathy, $n(\%)$ & & & & & & 0.472 \\
\hline Absent & $20(41 \%)$ & $8(67 \%)$ & $2(20 \%)$ & $4(27 \%)$ & $6(50 \%)$ & \\
\hline Mild & $17(35 \%)$ & $3(25 \%)$ & $5(50 \%)$ & $6(40 \%)$ & $3(25 \%)$ & \\
\hline Moderate & $6(12 \%)$ & $0(0 \%)$ & $1(10 \%)$ & $3(20 \%)$ & $2(17 \%)$ & \\
\hline Severe & $6(12 \%)$ & $1(8 \%)$ & $2(20 \%)$ & $2(13 \%)$ & $1(8 \%)$ & \\
\hline Lewy body, $n(\%)$ & & & & & & 0.726 \\
\hline Absent & $34(79 \%)$ & $8(80 \%)$ & $7(88 \%)$ & $11(85 \%)$ & $8(67 \%)$ & \\
\hline Present & $9(21 \%)$ & $2(20 \%)$ & $1(12 \%)$ & $2(15 \%)$ & $4(33 \%)$ & \\
\hline No data & 6 & 2 & 2 & 2 & 0 & \\
\hline Hippocampal TDP-43, $n(\%)$ & & & & & & 0.105 \\
\hline Absent & $28(68 \%)$ & $9(100 \%)$ & $6(75 \%)$ & $8(53 \%)$ & $5(56 \%)$ & \\
\hline Mild & $8(20 \%)$ & $0(0 \%)$ & $1(13 \%)$ & $6(40 \%)$ & $1(11 \%)$ & \\
\hline Moderate & $4(10 \%)$ & $0(0 \%)$ & $1(13 \%)$ & $1(7 \%)$ & $2(22 \%)$ & \\
\hline Severe & $1(2 \%)$ & $0(0 \%)$ & $0(0 \%)$ & $0(0 \%)$ & $1(11 \%)$ & \\
\hline No data & 8 & 3 & 2 & 0 & 3 & \\
\hline Hippocampal sclerosis, $n(\%)$ & & & & & & 0.363 \\
\hline Absent & $42(89 \%)$ & $10(100 \%)$ & $9(90 \%)$ & $14(93 \%)$ & $9(75 \%)$ & \\
\hline Present (unilateral or bilateral) & $5(11 \%)$ & $0(0 \%)$ & $1(10 \%)$ & $1(7 \%)$ & $3(25 \%)$ & \\
\hline No data & 2 & 2 & 0 & 0 & 0 & \\
\hline Small infarct, $n(\%)$ & & & & & & 0.253 \\
\hline Absent & $19(44 \%)$ & $5(50 \%)$ & $1(13 \%)$ & $7(54 \%)$ & $6(50 \%)$ & \\
\hline Present & $24(56 \%)$ & $5(50 \%)$ & $7(87 \%)$ & $6(46 \%)$ & $6(50 \%)$ & \\
\hline No data & 6 & 2 & 2 & 2 & 0 & \\
\hline \multicolumn{7}{|l|}{ Neuritic plaque, med (IQR) } \\
\hline Frontal cortex & $6.6(1.6-11.6)$ & $4.2(0.0-8.9)$ & $6.2(0.0-10.9)$ & $6.6(3.6-8.9)$ & $10.0(2.9-15.5)$ & 0.390 \\
\hline Temporal cortex & $6.4(1.6-11.0)$ & $6.0(0.0-11.0)$ & $5.4(0.4-8.6)$ & $6.4(2.4-7.4)$ & $9.9(5.7-13.9)$ & 0.396 \\
\hline Parietal cortex & $6.8(1.4-12.2)$ & $3.0(0.0-8.9)$ & $4.4(0.0-8.7)$ & $7.4(4.3-12.3)$ & $10.8(5.5-17.3)$ & 0.119 \\
\hline Amygdala & $4.2(0.4-8.0)$ & $3.9(0.0-5.1)$ & $4.3(0.6-8.1)$ & $2.8(1.1-8.2)$ & $6.7(3.2-8.8)$ & 0.400 \\
\hline Entorhinal cortex & $0.6(0.0-1.2)$ & $0.1(0.0-0.7)$ & $0.8(0.2-1.2)$ & $0.8(0.1-1.4)$ & $0.6(0.0-1.1)$ & 0.340 \\
\hline Hippocampus $^{3}$ & $0.0(0.0-0.7)$ & $0.0(0.0-0.0)$ & $0.0(0.0-0.7)$ & $0.0(0.0-1.3)$ & $0.0(0.0-1.1)$ & 0.581 \\
\hline Subiculum $^{3}$ & $0.6(0.0-1.6)$ & $0.0(0.0-0.6)$ & $0.8(0.6-1.6)$ & $0.8(0.0-2.1)$ & $0.6(0.0-1.0)$ & 0.380 \\
\hline \multicolumn{7}{|l|}{ Neurofibrillary tangle, med (IQR) } \\
\hline Frontal cortex & $0.2(0.0-1.8)$ & $0.0(0.0-1.1)^{\mathrm{a}}$ & $0.0(0.0-0.4)^{\mathrm{a}}$ & $0.2(0.0-1.3)^{\mathrm{a}}$ & $5.0(0.8-9.2)^{\mathrm{b}}$ & 0.011 \\
\hline Temporal cortex & $0.6(0.0-3.4)$ & $0.2(0.0-0.5)^{\mathrm{a}}$ & $0.5(0.0-1.5)^{\mathrm{a}}$ & $0.2(0.0-5.0)^{\mathrm{a}}$ & $5.1(1.5-18.9)^{\mathrm{b}}$ & 0.031 \\
\hline Parietal cortex & $0.4(0.0-2.6)$ & $0.0(0.0-0.6)^{\mathrm{a}}$ & $0.0(0.0-0.3)^{\mathrm{a}}$ & $0.6(0.0-2.7)^{\mathrm{a}, \mathrm{b}}$ & $2.5(0.4-6.5)^{\mathrm{b}}$ & 0.018 \\
\hline Amygdala & $9.2(2.4-27.8)$ & $3.1(1.6-11.0)$ & $9.8(3.8-24.6)$ & $8.0(1.5-22.7)$ & $23.9(10.6-40.5)$ & 0.062 \\
\hline Entorhinal cortex & $20.0(5.8-37.0)$ & $22.5(5.1-37.2)$ & $20.1(14.1-32.1)$ & $7.6(3.4-19.5)$ & $37.4(19.7-47.7)$ & 0.054 \\
\hline Hippocampus ${ }^{3}$ & $10.5(2.8-17.7)$ & $8.2(2.7-16.4)$ & $13.4(4.2-17.0)$ & $4.4(1.4-16.4)$ & $17.4(9.9-28.9)$ & 0.234 \\
\hline Subiculum $^{3}$ & $22.7(5.0-52.7)$ & $11.2(4.6-19.6)^{\mathrm{a}}$ & $37.2(9.8-57.0)^{\mathrm{a}, \mathrm{b}}$ & $18.7(3.1-27.4)^{\mathrm{a}}$ & $53.2(34.0-99.5)^{\mathrm{b}}$ & 0.032 \\
\hline Braak staging, n (\%) & & & & & & 0.036 \\
\hline I-II (transentorhinal) & $17(37 \%)$ & $7(58 \%)$ & $2(22 \%)$ & $7(47 \%)$ & $1(9 \%)$ & \\
\hline III-IV (limbic) & $15(33 \%)$ & $3(25 \%)$ & $6(67 \%)$ & $2(13 \%)$ & $4(36 \%)$ & \\
\hline V-VI (isocortical) & $14(30 \%)$ & $2(17 \%)$ & $1(11 \%)$ & $5(33 \%)$ & $6(55 \%)$ & \\
\hline No data ${ }^{3}$ & 3 & 0 & 1 & 1 & 1 & \\
\hline NIARI AD criterion, $n(\%)$ & & & & & & 0.202 \\
\hline No AD & $7(15 \%)$ & $3(25 \%)$ & $2(20 \%)$ & $1(8 \%)$ & $1(9 \%)$ & \\
\hline Low likelihood & $14(30 \%)$ & $5(42 \%)$ & $2(20 \%)$ & $6(46 \%)$ & $1(9 \%)$ & \\
\hline Intermediate likelihood & $12(26 \%)$ & $2(17 \%)$ & $5(50 \%)$ & $2(15 \%)$ & $3(27 \%)$ & \\
\hline High likelihood & $13(28 \%)$ & $2(17 \%)$ & $1(10 \%)$ & $4(31 \%)$ & $6(55 \%)$ & \\
\hline No data & 3 & 0 & 0 & 2 & 1 & \\
\hline
\end{tabular}

${ }^{1}$ Means and medians that do not share the same superscription are statistically different with pairwise comparison using Wilcoxon's rank sum test. ${ }^{2}$ Kruskal-Wallis test (continuous variables) and Fisher's exact test (categorical variables) was performed for comparisons among four groups. ${ }^{3}$ Neuritic plaques and neurofibrillary tangles in hippocampus and subiculum, including Braak staging, from three individuals (each from GDS 3, 4-5, 6-7) could not be reliably quantified/assessed due to severe hippocampal sclerosis. GDS, Global Deterioration Scale; IQR, Interquartile range; NIARI, National Institute on Aging-Reagan Institute; AD, Alzheimer's disease. 

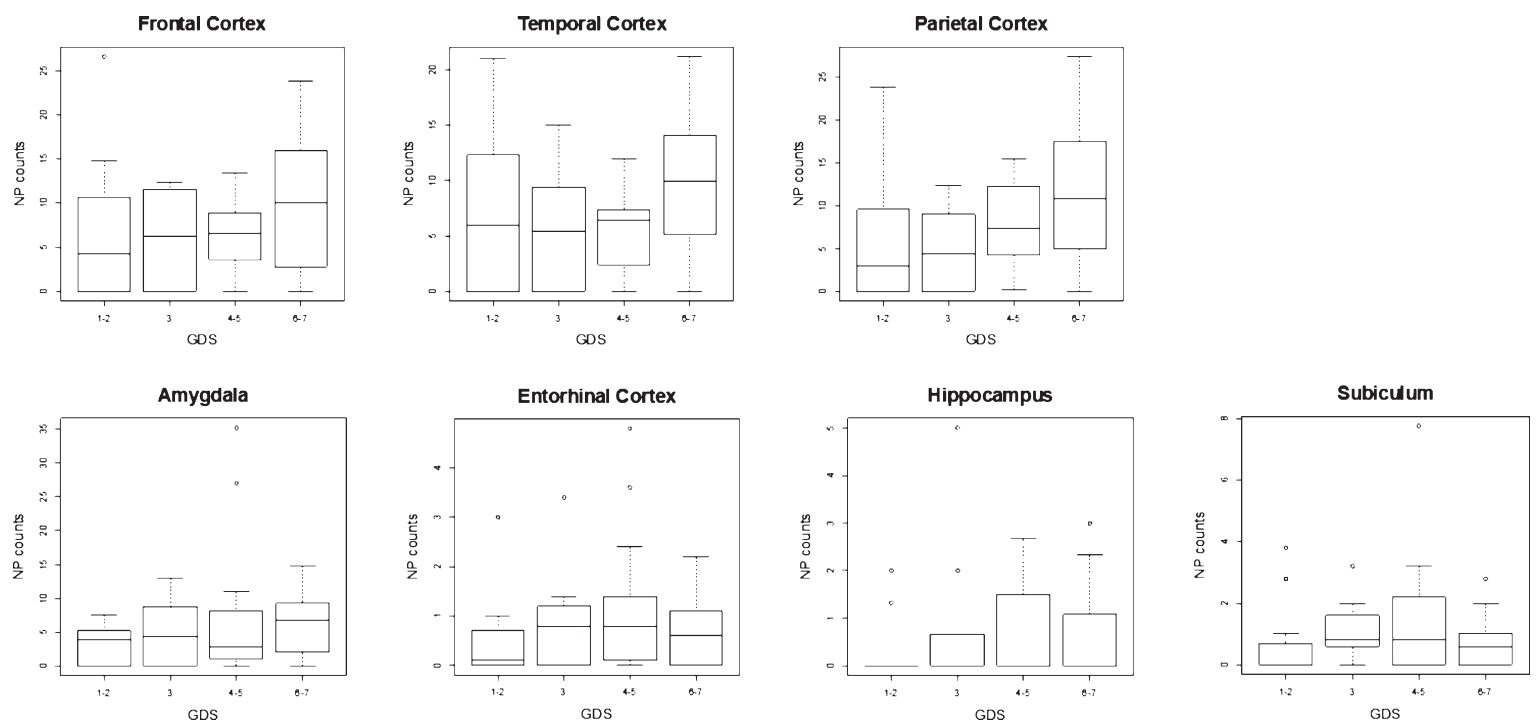

Fig. 1. Neuritic plaque (NP) counts in different regions of the brain. Global Deterioration Scale (GDS) 1-2: $n=12$, GDS 3: $n=10$, GDS 4-5: $n=15$, GDS 6-7: $n=12$.
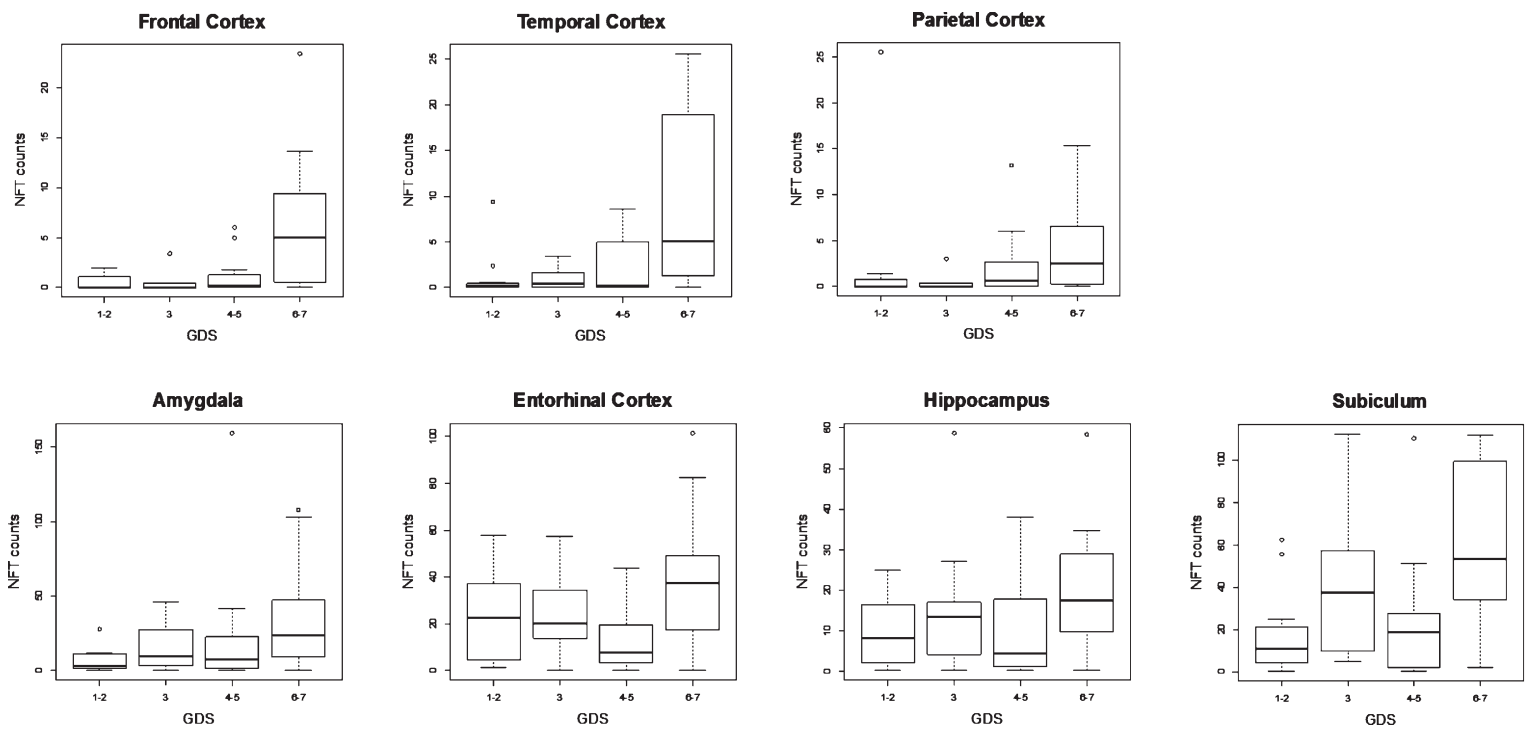

Fig. 2. Neurofibrillary tangle (NFT) counts in different regions of the brain. Global Deterioration Scale (GDS) 1-2: $n=12$, GDS 3: $n=10$, GDS 4-5: $n=15$, GDS 6-7: $n=12$.

atrophy was also related to significantly lower scores in memory, language, and activities of daily living $(p<0.05$, FDR $<0.15$ for all). Presence of ventricular dilation was significantly associated with lower scores in global cognition, executive function, and activities of daily living $(p<0.05$, FDR $<0.10$ for all). No association between cerebral atherosclerosis or LBP and any cognitive domain was observed. Lower scores in global cognition, memory, exec- utive function, and activities of daily living were observed in moderate CAA compared to those absent of CAA $(p<0.05$, FDR $<0.10$ for all). Similarly, lower performance in memory, visuospatial function, and attention/encoding was associated with presence of aberrant hippocampal TDP-43 or HS $(p<0.05$, FDR $<0.10$ for TDP-43; $p<0.05$, FDR $<0.20$ for HS), especially severe hippocampal TDP-43 and visuospatial function $(p<0.01, \mathrm{FDR}<0.05)$. How- 
ever, this association was established upon one subject who had severe hippocampal TDP-43 proteinopathy.

Higher NP counts in FC was associated with lower visuospatial function score $(p<0.05, \mathrm{FDR}>0.20)$, and higher NP counts in TC was associated with lower global cognition and visuospatial function scores $(p<0.05$, FDR $<0.15$ for both; Table 3 ). On the contrary, higher NP counts in PC were consistently related to worse performance in global cognition $(p<0.05$, FDR $<0.05)$, memory $(p<0.05$, FDR $<0.05)$, executive function $(p<0.05, \mathrm{FDR}<0.10)$, visuospatial function $(p<0.01$, FDR $<0.05)$. NP counts in Amy, Ent, Hip, and Sub were not statistically related to any cognitive domain, depression, or activities of daily living.

Compared to NP, associations between NFT counts and cognitive performance were more consistently observed. Averaged NFT counts in FC, TC, and PC were negatively associated with global cognition $(p<0.01, \mathrm{FDR}<0.01$ for TC; $p<0.001, \mathrm{FDR}<0.01$ for FC, PC), memory $(p<0.01$, FDR $<0.01$ for FC; $p<0.01, \mathrm{FDR}<0.05$ for TC, $\mathrm{PC})$, language $(p<0.05$, FDR $<0.05$ for FC, TC; $p<0.01$, FDR $<0.05$ for $\mathrm{PC})$, visuospatial function $(p<0.05, \mathrm{FDR}<0.10$ for $\mathrm{FC} ; p<0.01, \mathrm{FDR}<0.05$ for $\mathrm{TC} ; p<0.01$, FDR $<0.01$ PC), and activities of daily living $(p<0.01, \mathrm{FDR}<0.05$ for FC, TC, PC). NFT counts in PC was significantly associated with attention/encoding score $(p<0.01, \mathrm{FDR}<0.05)$. NFT counts in TC were also negatively associated with executive function $(p<0.05$, FDR $<0.10)$. Significant associations between higher NFT counts in Sub and lower scores in global cognition $(p<0.01$, FDR $<0.05)$, memory $(p<0.01$, FDR $<0.05)$, language $(p<0.05, \mathrm{FDR}<0.10)$, and activities of daily living $(p<0.05$, FDR $<0.10)$ were observed. NFT counts in Hip were also significantly associated with executive function $(p<0.05$, FDR $>0.20)$, as well as NFT counts in Amy and Ent with visuospatial function $(p<0.05$, FDR $<0.15$ for Amy; $p<0.05$, FDR $>0.20$ for Ent).

Advanced Braak staging (Braak staging V-VI) and NIARI AD criteria (high likelihood of $A D$ ) were both significantly associated with poor performance in global cognition $(p<0.05$, FDR $<0.05$ for Braak staging; $p<0.01$, FDR $<0.05$ for NIARI AD criteria) and memory $(p<0.01$, FDR $<0.05$ for Braak staging; $p<0.05$, FDR $<0.05$ for NIARI AD criteria). Advanced Braak stage was also significantly related to lower score in language $(p<0.05, \mathrm{FDR}<0.10)$, and both advanced Braak stage and NIARI AD criteria were related to lower score in visuospatial function $(p<0.05, \mathrm{FDR}<0.10$ for both). Depression was not significantly associated with any neuropathological variables measured in this present study.

\section{DISCUSSION}

\section{AD-type pathology in non-demented and demented centenarians}

Neuropathological changes have been previously described in centenarians pooled from three different cohorts including the GCS [16], the Nun Study $[20,21]$, and the UK-ADC [41], and its primary finding demonstrated that AD-type lesion (NP, NFT) was not universal in the oldest old [19]. In this current $\mathrm{CP}$ assessment in the GCS cohort, we observed that distributions of neuropathology were similar among centenarians who were rated by geriatric psychiatrists as having intact cognition, MCI, mild and severe dementia, with an exception of advanced NFT progression in the neocortex (FC, TC, PC) and Sub. For example, $45 \%$ of non-demented subjects had intermediate or high likelihood of $\mathrm{AD}$ according to the NIARI AD neuropathology criteria, which confirmed the finding from the $90+$ Study where the proportion was $49 \%$ [42]. There were two decedents categorized as high likelihood of AD and Braak staging $\mathrm{V}$, but both had normal cognition (GDS 1-2). Both subjects were Caucasian, high school graduates, and community-based dwellers, all of which were characteristics associated with better ratings of cognitive function in the GCS [17]. Our observations underline the heterogeneity of neuropathology and the possibility of living beyond 100 years without clinical manifestation of cognitive decline or dementia under certain degrees of neuropathological changes [5]. In line with our findings, an analysis in postmortem brains from 40 centenarians from the 100-Plus Study whose premortem MMSE score were $23.7 \pm 4.6$ (MMSE score: $24-30=$ normal cognition; 19-23 = mild; $10-18=$ moderate or $\leq 9=$ severe cognitive impairment) also demonstrated a wide range of AD-type pathology, but none had Braak staging V-VI $[24,43]$. Two out of six non-demented centenarians from the NECS also had significant AD neuropathological changes, but Braak staging was also limited to $\leq \mathrm{IV}$ [25]. In younger old adults, AD-type lesions may be present during preclinical AD stages without any signs of dementia unless severe neocortical AD-type lesions are observed [44-46]. Although rare, there were also reports on Braak staging V-VI subjects 
Table 3

Linear regression $\beta$ coefficients (standard error) demonstrating the relationship between neuropathological variables and composite scores of six cognitive domains, depression, and activities of daily living adjusted for sex, race, education, hypertension, and diabetes ${ }^{1}$

\begin{tabular}{|c|c|c|c|c|c|c|c|c|}
\hline Neuropathology & $\begin{array}{c}\text { Global } \\
\text { cognition } \\
(n=49)\end{array}$ & $\begin{array}{l}\text { Memory } \\
(n=49)\end{array}$ & $\begin{array}{l}\text { Executive } \\
\text { function } \\
(n=49)\end{array}$ & $\begin{array}{l}\text { Language } \\
(n=49)\end{array}$ & $\begin{array}{l}\text { Visuospatial } \\
\text { function } \\
(n=29)\end{array}$ & $\begin{array}{l}\text { Attention/ } \\
\text { Encoding } \\
(n=24)\end{array}$ & $\begin{array}{l}\text { Depression } \\
\quad(n=42)\end{array}$ & $\begin{array}{c}\text { Activities of } \\
\text { daily living } \\
(n=49)\end{array}$ \\
\hline \multicolumn{9}{|l|}{ Cerebral atrophy } \\
\hline Absent & 0.00 (ref) & 0.00 (ref) & 0.00 (ref) & 0.00 (ref) & 0.00 (ref) & 0.00 (ref) & 0.00 (ref) & 0.00 (ref) \\
\hline Mild & $-0.43(0.22)$ & $-0.61(0.24)^{*}$ & $-0.36(0.25)$ & $-0.46(0.22)^{*}$ & $-0.12(0.35)$ & $0.77(0.45)$ & $0.52(0.29)$ & $-0.63(0.28)^{*}$ \\
\hline Moderate & $-1.28(0.41)^{* *}$ & $-1.46(0.44)^{* *}$ & $-1.31(0.47)^{* *}$ & $-1.42(0.41)^{* * *}$ & $-2.27(0.91)^{*}$ & $1.75(1.49)$ & $0.52(0.58)$ & $-1.18(0.53) *$ \\
\hline Severe & $-1.15(0.44)^{*}$ & $-1.26(0.47)^{*}$ & $-1.12(0.50)^{*}$ & $-0.88(0.44)$ & $-0.78(0.90)$ & $-0.99(1.01)$ & $-0.98(0.89)$ & $-1.49(0.56)^{*}$ \\
\hline \multicolumn{9}{|l|}{ Ventricular dilation } \\
\hline Absent & 0.00 (ref) & 0.00 (ref) & 0.00 (ref) & 0.00 (ref) & 0.00 (ref) & 0.00 (ref) & 0.00 (ref) & 0.00 (ref) \\
\hline Present & $-0.73(0.30)^{*}$ & $-0.66(0.34)$ & $-0.72(0.34) *$ & $-0.78(0.30)^{*}$ & $-0.73(0.57)$ & $-0.74(0.78)$ & $0.73(0.45)$ & $-0.82(0.38)^{*}$ \\
\hline \multicolumn{9}{|c|}{ Cerebral atherosclerosis } \\
\hline Mild & 0.00 (ref) & 0.00 (ref) & 0.00 (ref) & 0.00 (ref) & 0.00 (ref) & 0.00 (ref) & 0.00 (ref) & 0.00 (ref) \\
\hline Moderate & $-0.15(0.26)$ & $-0.06(0.29)$ & $-0.08(0.29)$ & $-0.02(0.26)$ & $-0.17(0.48)$ & $-0.42(0.52)$ & $0.07(0.32)$ & $-0.04(0.33)$ \\
\hline Severe & $-0.45(0.60)$ & $-0.20(0.67)$ & $-0.19(0.67)$ & $0.22(0.61)$ & $0.11(1.07)$ & $-1.11(1.23)$ & $1.20(0.93)$ & $-0.20(0.75)$ \\
\hline \multicolumn{9}{|l|}{ Amyloid angiopathy } \\
\hline Absent & 0.00 (ref) & 0.00 (ref) & 0.00 (ref) & 0.00 (ref) & 0.00 (ref) & 0.00 (ref) & 0.00 (ref) & 0.00 (ref) \\
\hline Mild & $0.00(0.25)$ & $-0.27(0.27)$ & $0.01(0.26)$ & $-0.07(0.25)$ & $-0.23(0.38)$ & $-0.31(0.42)$ & $-0.14(0.32)$ & $0.14(0.30)$ \\
\hline Moderate & $-0.74(0.36)^{*}$ & $-0.87(0.40)^{*}$ & $-1.01(0.38)^{*}$ & $-0.55(0.37)$ & $-1.03(0.73)$ & $-1.57(1.00)$ & $-0.25(0.49)$ & $-0.98(0.44)^{*}$ \\
\hline Severe & $-0.17(0.36)$ & $-0.24(0.39)$ & $-0.11(0.38)$ & $-0.40(0.36)$ & $-0.09(1.02)$ & $-1.56(0.85)$ & $-0.24(0.53)$ & $-0.05(0.43)$ \\
\hline \multicolumn{9}{|l|}{ Lewy body } \\
\hline Absent & 0.00 (ref) & 0.00 (ref) & 0.00 (ref) & 0.00 (ref) & 0.00 (ref) & 0.00 (ref) & 0.00 (ref) & 0.00 (ref) \\
\hline Present & $-0.20(0.31)$ & $-0.15(0.33)$ & $0.13(0.34)$ & $-0.02(0.31)$ & $-0.66(0.73)$ & $-0.33(0.88)$ & $-0.76(0.42)$ & $-0.21(0.36)$ \\
\hline \multicolumn{9}{|c|}{ Hippocampal TDP-43 } \\
\hline Absent & 0.00 (ref) & 0.00 (ref) & 0.00 (ref) & 0.00 (ref) & 0.00 (ref) & 0.00 (ref) & 0.00 (ref) & 0.00 (ref) \\
\hline Mild & $-0.32(0.31)$ & $-0.71(0.32)^{*}$ & $-0.23(0.36)$ & $-0.35(0.32)$ & $-1.29(0.44)^{*}$ & $-1.59(0.62)^{*}$ & $-0.05(0.42)$ & $0.09(0.38)$ \\
\hline Moderate & $-0.67(0.44)$ & $-0.97(0.46)^{*}$ & $-0.36(0.52)$ & $-0.46(0.46)$ & no data & no data & $-0.67(0.76)$ & $-0.73(0.54)$ \\
\hline Severe & $-1.14(0.80)$ & $-1.25(0.83)$ & $-0.95(0.94)$ & $-1.00(0.84)$ & $-2.98(0.82)^{* * *}$ & $-1.26(1.16)$ & $0.51(1.01)$ & $-0.84(0.98)$ \\
\hline \multicolumn{9}{|c|}{ Hippocampal sclerosis } \\
\hline Absent & 0.00 (ref) & 0.00 (ref) & 0.00 (ref) & 0.00 (ref) & 0.00 (ref) & 0.00 (ref) & 0.00 (ref) & 0.00 (ref) \\
\hline Present & $-0.67(0.41)$ & $-0.88(0.44)^{*}$ & $-0.39(0.47)$ & $-0.46(0.41)$ & $-2.20(1.02)^{*}$ & $-1.44(1.34)$ & $-0.24(0.60)$ & $-0.70(0.51)$ \\
\hline \multicolumn{9}{|l|}{ Small infarct } \\
\hline Absent & 0.00 (ref) & 0.00 (ref) & 0.00 (ref) & 0.00 (ref) & 0.00 (ref) & 0.00 (ref) & 0.00 (ref) & 0.00 (ref) \\
\hline Present & $-0.18(0.26)$ & $-0.07(0.28)$ & $-0.16(0.29)$ & $-0.21(0.25)$ & $-0.05(0.46)$ & $0.49(0.53)$ & $-0.31(0.33)$ & $-0.28(0.30)$ \\
\hline \multicolumn{9}{|l|}{ Neuritic plaque $^{1}$} \\
\hline Frontal cortex & $-0.18(0.10)$ & $-0.16(0.11)$ & $-0.17(0.11)$ & $-0.14(0.10)$ & $-0.34(0.15)^{*}$ & $-0.35(0.18)$ & $-0.06(0.14)$ & $-0.14(0.13)$ \\
\hline Temporal cortex & $-0.20(0.10)^{*}$ & $-0.16(0.11)$ & $-0.21(0.11)$ & $-0.13(0.10)$ & $-0.41(0.15)^{*}$ & $-0.37(0.19)$ & $-0.12(0.13)$ & $-0.19(0.13)$ \\
\hline Parietal cortex & $-0.24(0.10)^{*}$ & $-0.28(0.10)^{*}$ & $-0.22(0.11)^{*}$ & $-0.16(0.10)$ & $-0.43(0.14)^{* *}$ & $-0.35(0.20)$ & $-0.10(0.13)$ & $-0.19(0.12)$ \\
\hline Amygdala & $-0.14(0.11)$ & $-0.21(0.12)$ & $-0.19(0.12)$ & $-0.08(0.12)$ & $-0.30(0.20)$ & $-0.34(0.23)$ & $-0.08(0.15)$ & $-0.15(0.14)$ \\
\hline
\end{tabular}


Table 3

(Continued)

\begin{tabular}{|c|c|c|c|c|c|c|c|c|}
\hline Neuropathology & $\begin{array}{l}\text { Global } \\
\text { cognition } \\
(n=49)\end{array}$ & $\begin{array}{l}\text { Memory } \\
(n=49)\end{array}$ & $\begin{array}{l}\text { Executive } \\
\text { function } \\
(n=49)\end{array}$ & $\begin{array}{c}\text { Language } \\
(n=49)\end{array}$ & $\begin{array}{l}\text { Visuospatial } \\
\text { function } \\
(n=29) \\
\end{array}$ & $\begin{array}{c}\text { Attention/ } \\
\text { Encoding } \\
(n=24)\end{array}$ & $\begin{array}{l}\text { Depression } \\
(n=42)\end{array}$ & $\begin{array}{l}\text { Activities of } \\
\text { daily living } \\
(n=49)\end{array}$ \\
\hline Entorhinal cortex & $-0.28(0.24)$ & -0.40 & $-0.29(0.26)$ & $-0.31(0.23)$ & $-0.47(0.41)$ & $-0.76(0.45)$ & $0.00(0.32)$ & $-0.18(0.30)$ \\
\hline Hippocampus $^{2}$ & $-0.05(0.24)$ & $(0.25)-0.21(0.26)$ & $-0.21(0.26)$ & $0.13(0.24)$ & $-0.15(0.39)$ & $0.57(0.50)$ & $-0.42(0.27)$ & $-0.20(0.29)$ \\
\hline Subiculum $^{2}$ & $-0.02(0.22)$ & $-0.20(0.24)$ & $-0.09(0.24)$ & $0.00(0.22)$ & $-0.66(0.44)$ & $-0.90(0.68)$ & $-0.29(0.27)$ & $-0.09(0.27)$ \\
\hline \multicolumn{9}{|l|}{ Neurofibrill ary tangle $^{1}$} \\
\hline Frontal cortex & $-0.44(0.12)^{* * *}$ & $-0.45(0.14)^{* *}$ & $-0.27(0.08)$ & $-0.31(0.13)^{*}$ & $-0.52(0.25)^{*}$ & $-0.39(0.34)$ & $0.13(0.24)$ & $-0.39(0.16)^{* *}$ \\
\hline Temporal cortex & $-0.37(0.10)^{* *}$ & $-0.37(0.12)^{* *}$ & $-0.26(0.13)^{*}$ & $-0.29(0.11)^{*}$ & $-0.51(0.19)^{* *}$ & $-0.35(0.30)$ & $0.04(0.19)$ & $-0.36(0.14)^{* *}$ \\
\hline Parietal cortex & $-0.43(0.12)^{* * *}$ & $-0.39(0.13)^{* *}$ & $-0.27(0.14)$ & $-0.34(0.12)^{* *}$ & $-0.66(0.18)^{* *}$ & $-0.75(0.32)^{* *}$ & $0.07(0.22)$ & $-0.40(0.15)^{* *}$ \\
\hline Amygdala & $-0.17(0.08)^{*}$ & $-0.18(0.09)$ & $-0.12(0.09)$ & $-0.13(0.08)$ & $-0.34(0.13)^{*}$ & $-0.18(0.19)$ & $0.05(0.11)$ & $-0.20(0.10)$ \\
\hline Entorhinal cortex & $-0.10(0.09)$ & $-0.07(0.10)$ & $-0.01(0.10)$ & $-0.12(0.09)$ & $-0.41(0.18)^{*}$ & $-0.17(0.25)$ & $-0.03(0.12)$ & $-0.11(0.11)$ \\
\hline Hippocampus $^{2}$ & $-0.15(0.11)$ & $-0.25(0.11)^{*}$ & $-0.02(0.12)$ & $-0.14(0.11)$ & $-0.16(0.17)$ & $-0.17(0.21)$ & $-0.03(0.13)$ & $-0.08(0.13)$ \\
\hline Subiculum $^{2}$ & $-0.24(0.09)^{* *}$ & $-0.30(0.09) * *$ & $-0.15(0.10)$ & $-0.20(0.09)^{*}$ & $-0.27(0.15)$ & $-0.08(0.19)$ & $-0.06(0.12)$ & $-0.25(0.11)^{*}$ \\
\hline \multicolumn{9}{|l|}{ Braak staging $^{2}$} \\
\hline I-II (transentorhinal) & 0.00 (ref) & 0.00 (ref) & 0.00 (ref) & 0.00 (ref) & 0.00 (ref) & 0.00 (ref) & 0.00 (ref) & 0.00 (ref) \\
\hline III-IV (limbic) & $-0.16(0.28)$ & $-0.15(0.29)$ & $-0.06(0.33)$ & $-0.05(0.28)$ & $-0.39(0.41)$ & $0.12(0.57)$ & $-0.27(0.36)$ & $-0.25(0.36)$ \\
\hline V-VI (isocortical) & $-0.73(0.28) * 0$ & $-0.91(0.29)^{* *}$ & $-0.41(0.33)$ & $-0.60(0.29)^{*}$ & $-1.07(0.43)^{*}$ & $-0.55(0.70)$ & $-0.13(0.38)$ & $-0.61(0.36)$ \\
\hline \multicolumn{9}{|l|}{ NIARI AD criterion } \\
\hline No AD & .00 (ref) & 0.00 (ref) & 0.00 (ref) & 0.00 (ref) & 0.00 (ref) & 0.00 (ref) & 0.00 (ref) & 0.00 (ref) \\
\hline Low likelihood & $-0.22(0.31)$ & $-0.13(0.36)$ & $-0.32(0.37)$ & $0.05(0.33)$ & $0.46(0.53)$ & $-0.33(0.76)$ & $-0.75(0.42)$ & $-0.07(0.44)$ \\
\hline Intermediate likelihood & $-0.49(0.33)$ & $-0.41(0.38)$ & $-0.58(0.40)$ & $-0.17(0.35)$ & $-0.42(0.49)$ & $-0.87(0.77)$ & $-0.56(0.44)$ & $-0.45(0.46)$ \\
\hline High likelihood & $-0.95(0.32)^{* *}$ & $-0.99(0.37) *$ & $-0.72(0.39)$ & $-0.66(0.34)$ & $-1.14(0.48)^{*}$ & $-1.22(0.94)$ & $-0.57(0.46)$ & $-0.69(0.45)$ \\
\hline
\end{tabular}

${ }^{*} p<0.05,{ }^{* *} p<0.01,{ }^{* * *} p<0.001$. Texts in bold: FDR $<0.05$ after an adjustment for multiple comparisons across domains. ${ }^{1}$ Neuritic plaques and neurofibrillary tangles were log transformed with $\log (x+1)$ in the regression models. ${ }^{2}$ Neuritic plaques and neurofibrillary tangles in hippocampus and subiculum, including Braak staging, from three individuals (each from GDS 3, 4-5, 6-7) could not be reliably quantified/assessed due to severe hippocampal sclerosis. GDS, Global Deterioration Scale; IQR: Interquartile range; NIARI, National Institute on Aging-Reagan Institute; $\mathrm{AD}$, Alzheimer's disease. 
who appeared to be clinically non-demented across multiple studies [46]. A case report from the Nun Study revealed a subject who had excellent cognitive performance up until death at age 85 with an abundance of neocortical senile plaques and Braak staging VI at postmortem examination [20]. A resistance to the expression of symptoms in the face of neuropathology has been previously described as cognitive reserve by Stern [47], which is associated with characteristics such as high education, intelligence, socioeconomic status, and daily tasks that are cognitively demanding. Our observations among centenarians without dementia also supported the theory of cognitive reserve widely accepted in younger old adults, although it is still undetermined if higher cognitive reserve prevents or merely delays the commencement of age-related cognitive impairment.

We also observed a wide range of AD-type pathology in demented centenarians. Even in cases rated as having severe dementia (GDS 6-7) two of 12 centenarians were free of NFT in the neocortex and NP in any brain region analyzed, which were likely to be cases of other forms of dementia given both decedents had cerebral atherosclerosis and infarctions, and one also had cerebral atrophy. It is important to point out that GDS rating does not distinguish among types of dementia [30]. Previous analysis demonstrated extensive concurrence of cerebrovascular disease, AD, HS, and Lewy body dementia pathologies in nonagenarian, centenarian, and supercentenarian ( $\geq 110$ years) brains $[11,19,24,42]$. Although single neuropathological entities (except neocortical NFT) were not associated with dementia rating in the GCS (Table 2), all centenarians who were absent of dementia (GDS 1-3) also had low degree of neuronal loss (absent of ventricular dilation and absent or low cerebral atrophy). All subjects who were cognitively intact (GDS 1-2) were also absent of HS and hippocampal TDP-43 proteinopathy. The accumulation of concomitant pathologies other than $\mathrm{AD}$-type lesions due to extreme aging may elicit the manifestation of dementia symptoms even with an absence or a low degree of AD-type pathology [48-50]. For example, the relationship between HS and lower cognitive performance among centenarians from the Nun Study and the UK-ADC were also independent of NFT and NP [36], to the extent that Crystal et al suggested all subjects with HS were demented [51]. Moreover, although the risk of $\mathrm{AD}$ increases as age increases [3], the prevalence of AD-type pathological diagnosis at autopsy seems to decline in many cohorts of nonagenarians and cen- tenarians while the prevalence of non-AD dementia may be as high as $50 \%$ [4, 22, 25, 36, 42, 51, 52]. In the GCS, $38 \%$ of demented centenarians (GDS 4-7) were diagnosed with either absence or low likelihood of AD according to the NIARI criteria [39, 53]. Individuals prone to develop $\mathrm{AD}$ may be more likely to die at younger ages and may explain decreased incidence rates at advanced ages [54]. Epidemiological and clinical studies, including ours, suggest the pathophysiology of dementia in centenarians is complex and heterogeneous due to age-related non-AD pathological changes, less pertinent to single pathological entities, and may be different from younger old adults due to their increased resistance to biological and psychological stress as demonstrated by the ability to live beyond 100 years [7].

A nonlinear progression of NP and NFT during the progression of $\mathrm{AD}$ has previously been reported in younger old adults [50]. In our present study, a sharp increase in neocortical Sub NFT (as well as a trend in Amy and Ent) was observed in the severe dementia cases (GDS 6-7), consistent with Braak and Braak's description of neuropathological staging of AD [38]. Neocortical NFT has been consistently associated with dementia status across other studies in the oldest old [9, 10, 14, 24, 42, 55]. We did not observe a significant increase in NP in neocortices or NFT in other brain regions except Sub during earlier stages of $\mathrm{AD}$ as observed in younger old adults [50]. This could be explained by GDS's inability of distinguishing AD from non-AD cases [30]. Nevertheless, it has been proposed that the oldest old might have a different neuropathological progression from younger old adults $[6,7]$, and the strength of the association between AD-type pathology and cognition was reported to decline with age [22, 52]. Still, NP lesion appeared to be related to cognitive status in some oldest old studies to a certain extent, but the association was stronger with NFT [14, 42, 55]. We also observed that neocortical NFT was also more consistently related to cognitive status than NP in the GCS. Moreover, four other studies in the oldest old also supported our finding that NFT in Hip section CA1 was not associated with cognitive status $[9,14$, $15,56]$. This is different from the findings in younger old adults where a quick NFT invasion of CA1 is observed with advancing dementia [6, 7].

\section{Neuropathology and objective test performance}

Similar to GDS, which was subjectively assessed by geriatric psychologists in the GCS, we observed 
that neocortical NFT, and to a lesser extent for NP, was related to poor performance in multiple cognitive domains and activities of daily living measured by cognitive performance tests. Apart from our study, only one other centenarian study, the 100-Plus Study, reported CP correlations with different cognitive domains [24]. In the 100-Plus Study, advanced Braak staging, and to a much lesser extent for $A \beta$ pathology, were associated with lower performance on the MMSE, the Visual Association Test (VAT), and the Clock Drawing Test (CDT), though these associations did not reach statistical significance. MMSE is a measure of global cognition [57], VAT is a test for episodic memory [58], and CDT measures visuospatial and executive function [59]. Performance on all of these cognitive domains, except executive function, was negatively associated with neocortical NFT load in the GCS centenarians. We also observed that Braak staging V-VI (neocortical) and NIARI's "high likelihood of AD" were specifically related to deficits in global cognition and memory but not other cognitive domains after FDR adjustment. The CP differences between NFT and Braak staging could possibly be explained by a decreased sensitivity after summarizing a continuous NFT load to an ordinal Braak staging. Nevertheless, Gold et al suggested that Braak staging might not be accurately predictive of cognitive abilities in centenarians and different neuropathological criteria should be considered for the oldest-old [12].

Apart from NP and NFT, moderate and severe cerebral atrophy was significantly associated with poor performance across multiple cognitive domains and activities of daily living. Similarly, ventricular dilation, also a measure of neuronal loss, had a borderline association with dementia status $(p=0.065)$. However, it was questionable if neuronal loss served as an independent predictor of cognitive status since a correlative trend was observed between ventricular dilation and NFT in FC, TC, PC, and Sub $(p<0.10$, Supplementary Table 6). This observation contradicted previous report on the dissociation between neuronal loss and NFT [15]. A lack of region-specific assessment also hindered the ability to compare our findings with other oldest-old studies. In one study, neuronal count in Ent and Hip were not significantly different among demented and non-demented subjects [56], while significant neuronal loss in Ent, FC, TC, but not Hip and Sub was observed among demented subjects in a different cohort [15]. Furthermore, severity of CAA was strongly associated with worse performance on CDT (visuospatial and executive function) in the 100-Plus Study [24]. In the GCS, moderate CAA was associated with poor performance in global cognition, memory, executive function, and activities of daily living. Findings form these two centenarian studies differed from findings in younger old subjects where most of individuals with CAA remained asymptomatic [60]. Similar to CAA, the association between HS or hippocampal TDP-43 pathology and poor cognition was not consistently observed in the GCS as it was reported previously [36], likely due to limited numbers of severe cases or the heterogenous pathophysiology of dementia in the oldest-old as mentioned earlier [22, $25,51]$.

\section{Study limitations}

General limitations in the CP studies of $\mathrm{AD}$ and dementia have been thoroughly described by Nelson et al. [50]. Similar to other reports, NP and NFT were analyzed quasi-linearly with regards to cognitive function for the purpose of $\mathrm{CP}$ correlations even though $\mathrm{AD}$ pathology progresses non-linearly during different stages of the disease. Our sample size was relatively small, especially cases of severe pathologies, and due to high cases of missing values variables such as APOE genotype, alcohol use, and smoking status were not controlled for. Cognitive data were derived from the assessment within one year prior to death for all subjects, but a terminal drop in cognitive function within the final year of life was previously observed in older individuals [61]. Cognitive tests may have different sensitivity among demented and non-demented subjects, and their application to centenarians is scarcely explored. Sixty-one percent of subjects, mostly those with dementia, also did not complete the entire testing battery (Supplementary Table 2). However, cognitive domain z-scores could be calculated from other cognitive tests with available data. Finally, limitations in the extrapolation of findings in centenarians needed to be highlighted. CP findings in the GCS centenarians could not be directly compared with lesser-aged cohorts since neuropathological assessment was not performed in those who may share similar social and biological factors relevant to neuropathological and cognitive outcomes [31]. Longevity-associated characteristics may disengage findings in centenarians from younger populations (i.e., survivorship bias). Nevertheless, as the world population is aging and centenarians are the fastest-growing demographic in developed nations [7], research findings in this unique 
group of population will become more relevant to the general population.

In summary, we have observed that neuropathological changes, mainly presence of neocortical NFT, and to a lesser extent (possibly due to their low prevalence) neocortical NP, measures of neuronal loss, CAA, HS and hippocampal TDP-43 proteinopathy were associated with severe dementia and poor performance in multiple cognitive domains in centenarians. However, AD-type pathology was not the only variable that explained cognitive impairment, which was also observed in other oldest old studies $[22,52]$. The wide ranges of AD-type neuropathological changes observed in non-demented subjects supported the theory of cognitive reserve, while wide ranges of AD-type neuropathology observed in demented subjects supported the complexity and heterogeneity of pathophysiology of dementia in the oldest old. Our observations supported that CP correlations in the oldest old may be different from younger older adults and warranted further investigation of characteristics associated with cognitive reserve and the pathophysiology of dementia in this unique population.

\section{ACKNOWLEDGMENTS}

Funding sources are from NIH 1P01-AG17553, USDA 8050-51000-95-01 S, and Abbott Nutrition. We would like to acknowledge the late Dr. William Markesbery, who served as the neuropathologist for the Georgia Centenarian Study.

Authors' disclosures available online (https:// www.j-alz.com/manuscript-disclosures/18-1110r2).

\section{SUPPLEMENTARY MATERIAL}

The supplementary material is available in the electronic version of this article: http://dx.doi. org/10.3233/JAD-181110.

\section{REFERENCES}

[1] Robine J-M, Cubaynes S (2017) Worldwide demography of centenarians. Mech Ageing Dev 165, 59-67.

[2] Willcox DC, Willcox BJ, Poon LW (2010) Centenarian studies: important contributors to our understanding of the aging process and longevity. Curr Gerontol Geriatr Res 2010, 1-6.

[3] Guerreiro R, Bras J (2015) The age factor in Alzheimer's disease. Genome Med 7, 106.

[4] Andersen-Ranberg K, Vasegaard L, Jeune B (2001) Dementia is not inevitable: a population-based study of Danish centenarians. J Gerontol B Psychol Sci Soc Sci 56, 152-159.
[5] Qiu C, Fratiglioni L (2018) Aging without dementia is achievable: current evidence from epidemiological research. J Alzheimers Dis 62, 933-942.

[6] Imhof A, Kövari E, von Gunten A, Gold G, Rivara CB, Herrmann FR, Hof PR, Bouras C, Giannakopoulos P (2007) Morphological substrates of cognitive decline in nonagenarians and centenarians: a new paradigm? J Neurol Sci 257, $72-79$.

[7] von Gunten A, Ebbing K, Imhof A, Giannakopoulos P, Kövari E (2010) Brain aging in the oldest-old. Curr Gerontol Geriatr Res 2010, 1-10.

[8] Serrano-Pozo A, Frosch MP, Masliah E, Hyman BT (2011) Neuropathological alterations in Alzheimer disease. Cold Spring Harb Perspect Med 1, a006189.

[9] Itoh Y, Yamada M, Suematsu N, Matsushita M, Otomo E (1998) An immunohistochemical study of centenarian brains: a comparison. J Neurol Sci 157, 73-81.

[10] Mizutani T, Shimada H (1992) Neuropathological background of twenty-seven centenarian brains. J Neurol Sci 108, 168-177.

[11] Takao M, Hirose N, Arai Y, Mihara B, Mimura M (2016) Neuropathology of supercentenarians - four autopsy case studies. Acta Neuropathol Commun 4, 97.

[12] Gold G, Bouras C, Kövari E, Canuto A, Glaría BG, Malky A, Hof PR, Michel JP, Giannakopoulos P (2000) Clinical validity of Braak neuropathological staging in the oldestold. Acta Neuropathol 99, 579-582, discussion 583-584.

[13] Delaère P, He Y, Fayet G, Duyckaerts C, Hauw JJ (1993) Beta A4 deposits are constant in the brain of the oldest old: an immunocytochemical study of 20 French centenarians. Neurobiol Aging 14, 191-194.

[14] Green MS, Kaye JA, Ball MJ (2000) The Oregon brain aging study: neuropathology accompanying healthy aging in the oldest old. Neurology 54, 105-13.

[15] Giannakopoulos P, Hof PR, Kovari E, Vallet PG, Herrmann FR, Bouras C (1996) Distinct patterns of neuronal loss and Alzheimer's disease lesion distribution in elderly individuals older than 90 years. J Neuropathol Exp Neurol 55, 1210-1220.

[16] Poon LW, Clayton GM, Martin P, Johnson MA, Courtenay BC, Sweaney AL, Merriam SB, Pless BS, Thielman SB (1992) The Georgia Centenarian Study. Int J Aging Hum Dev 34, 1-17.

[17] Poon LW, Woodard JL, Stephen Miller L, Green R, Gearing M, Davey A, Arnold J, Martin P, Siegler IC, Nahapetyan L, Kim YS, Markesbery W (2012) Understanding dementia prevalence among centenarians. J Gerontol A Biol Sci Med Sci 67, 358-365.

[18] Davey A, Dai T, Woodard JL, Miller LS, Gondo Y, Johnson MA, Hausman DB, Martin P, Green RC, Allen RH, Stabler SP, Poon LW, Georgia Centenarian Study (2013) Profiles of cognitive functioning in a population-based sample of centenarians using factor mixture analysis. Exp Aging Res 39, 125-144.

[19] Neltner JH, Abner EL, Jicha GA, Schmitt FA, Patel E, Poon LW, Marla G, Green RC, Davey A, Johnson MA, Jazwinski SM, Kim S, Davis D, Woodard JL, Kryscio RJ, Van Eldik LJ, Nelson PT (2016) Brain pathologies in extreme old age. Neurobiol Aging 37, 1-11.

[20] Snowdon DA (1997) Aging and Alzheimer's disease: lessons from the Nun Study. Gerontologist 37, 150-156.

[21] Tyas SL, Snowdon DA, Desrosiers MF, Riley KP, Markesbery WR (2007) Healthy ageing in the Nun Study: definition and neuropathologic correlates. Age Ageing 36, 650-655. 
[22] Savva GM, Wharton SB, Ince PG, Forster G, Matthews FE, Brayne C, Medical Research Council Cognitive Function and Ageing Study (2009) Age, neuropathology, and dementia. N Engl J Med 360, 2302-2309.

[23] Neuropathology Group of the Medical Research Council Cognitive Function and Aging Study (MRC CFAS) (2001) Pathological correlates of late-onset dementia in a multicentre, community-based population in England and Wales. Lancet 357, 169-175.

[24] Ganz AB, Beker N, Hulsman M, Sikkes S, Netherlands Brain Bank, Scheltens P, Smit AB, Rozemuller AJM, Hoozemans JJM, Holstege H (2018) Neuropathology and cognitive performance in self-reported cognitively healthy centenarians. Acta Neuropathol Commun 6, 64.

[25] Silver MH, Newell K, Brady C, Hedley-White ET, Perls TT (2002) Distinguishing between neurodegenerative disease and disease-free aging: correlating neuropsychological evaluations and neuropathological studies in centenarians. Psychosom Med 64, 493-501.

[26] Snowdon DA (2003) Healthy aging and dementia: findings from the Nun Study. Ann Intern Med 139(5 Part 2), 450-454.

[27] den Dunnen WFA, Brouwer WH, Bijlard E, Kamphuis J, van Linschoten K, Eggens-Meijer E, Holstege G (2008) No disease in the brain of a 115-year-old woman. Neurobiol Aging 29, 1127-1132.

[28] García-Sierra F, Hauw JJ, Duyckaerts C, Wischik CM, Luna-Muñoz J, Mena R (2000) The extent of neurofibrillary pathology in perforant pathway neurons is the key determinant of dementia in the very old. Acta Neuropathol 100, 29-35.

[29] Poon LW, Jazwinski M, Green RC, Woodard JL, Martin P, Rodgers WL, Johnson MA, Hausman D, Arnold J, Davey A, Batzer MA, Markesbery WR, Gearing M, Siegler IC, Reynolds S, Dai J (2007) Methodological considerations in studying centenarians: lessons learned from the Georgia Centenarian Studies. Annu Rev Gerontol Geriatr 27, 231264.

[30] Reisberg B, Ferris S, de Leon M, Crook T (1982) The Global Deterioration Scale for assessment of primary degenerative dementia. Am J Psychiatry 139, 1136-1139.

[31] Johnson EJ, Vishwanathan R, Johnson MA, Hausman DB, Davey A, Scott TM, Green RC, Miller S, Gearing $\mathrm{M}$, Woodard J, Nelson PT, Chung H-Y, Schalch W, Wittwer J, Poon LW (2013) Relationship between serum and brain carotenoids, $\alpha$-tocopherol, and retinol concentrations and cognitive performance in the oldest old from the Georgia Centenarian Study. J Aging Res 2013, $1-13$.

[32] Bowman GL, Silbert LC, Howieson D, Dodge HH, Traber MG, Frei B, Kaye JA, Shannon J, Quinn JF (2012) Nutrient biomarker patterns, cognitive function, and MRI measures of brain aging. Neurology 78, 241-249.

[33] Apostolova LG, Green AE, Babakchanian S, Hwang KS, Chou Y-Y, Toga AW, Thompson PM (2012) Hippocampal atrophy and ventricular enlargement in normal aging, mild cognitive impairment and Alzheimer's disease. Alzheimer Dis Assoc Disord 26, 17-27.

[34] McKeith I, Ballard CG, Perry RH, Ince PG, O'Brien JT, Neill D, Lowery K, Jaros E, Barber R, Thompson P, Swann A, Fairbairn AF, Perry EK (2000) Prospective validation of consensus criteria for the diagnosis of dementia with Lewy bodies. Neurology 54, 1050-1058.

[35] McKeith I, Mintzer J, Aarsland D, Burn D, Chiu H, CohenMansfield J, Dickson D, Dubois B, Duda JE, Feldman H, Gauthier S, Halliday G, Lawlor B, Lippa C, Lopez
OL, Carlos Machado J, O'Brien J, Playfer J, Reid W (2004) Dementia with Lewy bodies. Lancet Neurol 3, 19-28.

[36] Nelson PT, Schmitt FA, Lin Y, Abner EL, Jicha GA, Patel E, Thomason PC, Neltner JH, Smith CD, Santacruz KS, Sonnen JA, Poon LW, Gearing M, Green RC, Woodard JL, Van Eldik LJ, Kryscio RJ (2011) Hippocampal sclerosis in advanced age: clinical and pathological features. Brain 134, 1506-1518

[37] Nelson PT, Smith CD, Abner EL, Wilfred BJ, Wang WX, Neltner JH, Baker M, Fardo DW, Kryscio RJ, Scheff SW, Jicha GA, Jellinger KA, Van Eldik LJ, Schmitt FA (2013) Hippocampal sclerosis of aging, a prevalent and high-morbidity brain disease. Acta Neuropathol 126, 161-177.

[38] Braak H, Braak E (1991) Neuropathological stageing of Alzheimer-related changes. Acta Neuropathol 82, 239-259.

[39] Montine TJ, Phelps CH, Beach TG, Bigio EH, Cairns NJ, Dickson DW, Duyckaerts C, Frosch MP, Masliah E, Mirra SS, Nelson PT, Schneider JA, Thal DR, Trojanowski JQ, Vinters HV, Hyman BT (2012) National Institute on Aging-Alzheimer's Association guidelines for the neuropathologic assessment of Alzheimer's disease: a practical approach. Acta Neuropathol 123, 1-11.

[40] Mirra SS, Heyman A, McKeel D, Sumi SM, Crain BJ, Brownlee LM, Vogel FS, Hughes JP, van Belle G, Berg L (1991) The Consortium to Establish a Registry for Alzheimer's Disease (CERAD). Part II. Standardization of the neuropathologic assessment of Alzheimer's disease. Neurology 41, 479-486.

[41] A Schmitt F, T Nelson P, Abner E, Scheff S, A Jicha G, Smith C, Cooper G, Mendiondo M, Danner DD, Van Eldik LJ, Caban-Holt A, Lovell MA, Kryscio RJ (2012) University of Kentucky Sanders-Brown healthy brain aging volunteers: donor characteristics, procedures and neuropathology. Curr Alzheimer Res 9, 724-733.

[42] Corrada MM, Berlau DJ, Kawas CH (2012) A populationbased clinicopathological study in the oldest-old: The 90+Study. Curr Alzheimer Res 9, 709-717.

[43] Holstege H, Hoozemans JMM, van Woerden N, Wemmenhove E, Pieterse K, Schouten K, Meijers-Heijboer H, Scheltens P, Rozemuller A (2015) Pathology of cognitively healthy centenarians. Alzheimers Demet 11, 257.

[44] Thal DR, Del Tredici K, Braak H (2004) Neurodegeneration in normal brain aging and disease. Sci Aging Knowl Environ 23, pe26.

[45] Jicha GA, Abner EL, Schmitt FA, Kryscio RJ, Riley KP, Cooper GE, Stiles N, Mendiondo MS, Smith CD, Van Eldik LJ, Nelson PT (2012) Preclinical AD Workgroup staging: pathological correlates and potential challenges. Neurobiol Aging 33, 622.e1-622.e16.

[46] Nelson PT, Alafuzoff I, Bigio EH, Bouras C, Braak H, Cairns NJ, Castellani RJ, Crain BJ, Davies P, Del Tredici K, Duyckaerts C, Frosch MP, Haroutunian V, Hof PR, Hulette CM, Hyman BT, Iwatsubo T, Jellinger KA, Jicha GA, Kövari E, Kukull WA, Leverenz JB, Love S, Mackenzie IR, Mann DM, Masliah E, McKee AC, Montine TJ, Morris JC, Schneider JA, Sonnen JA, Thal DR, Trojanowski JQ, Troncoso JC, Wisniewski T, Woltjer RL, Beach TG (2012) Correlation of Alzheimer disease neuropathologic changes with cognitive status: a review of the literature. $J$ Neuropathol Exp Neurol 71, 362-381.

[47] Stern Y (2002) What is cognitive reserve? Theory and research application of the reserve concept. J Int Neuropsychol Soc 8, 448-460. 
[48] Arlt S (2013) Non-Alzheimer's disease-related memory impairment and dementia. Dialogues Clin Neurosci 15, 465-473.

[49] Kapasi A, DeCarli C, Schneider JA (2017) Impact of multiple pathologies on the threshold for clinically overt dementia. Acta Neuropathol 134, 171-186.

[50] Nelson PT, Braak H, Markesbery WR (2009) Neuropathology and cognitive impairment in Alzheimer disease: a complex but coherent relationship. J Neuropathol Exp Neurol 68, 1-14.

[51] Crystal HA, Dickson D, Davies P, Masur D, Grober E, Lipton RB (2000) The relative frequency of dementia of unknown etiology increases with age and is nearly $50 \%$ in nonagenarians. Arch Neurol 57, 713-719.

[52] Haroutunian V, Schnaider-Beeri M, Schmeidler J, Wysocki M, Purohit DP, Perl DP, Libow LS, Lesser GT, Maroukian M, Grossman HT (2008) Role of the neuropathology of Alzheimer disease in dementia in the oldest-old. Arch Neurol 65, 1211-1217.

[53] Hyman BT, Trojanowski JQ (1997) Consensus recommendations for the postmortem diagnosis of Alzheimer's disease. J Neuropathol Exp Neurol 56, 1095-1097.

[54] Perls T (2004) Centenarians who avoid dementia. Trends Neurosci 27, 633-636.

[55] Giannakopoulos P, Hof PR, Giannakopoulos AS, Herrmann FR, Michel JP, Bouras C (1995) Regional distribution of neurofibrillary tangles and senile plaques in the cerebral cortex of very old patients. Arch Neurol 52, 1150-1159.

[56] von Gunten A, Kövari E, Rivara CB, Bouras C, Hof PR, Giannakopoulos P (2005) Stereologic analysis of hippocampal Alzheimer's disease pathology in the oldest-old: evidence for sparing of the entorhinal cortex and CA1 field. Exp Neurol 193, 198-206.

[57] Folstein M, Folstein M, McHugh P (1975) "Mini mental state". A practical method for grading the cognitive state of patients for the clinician. J Psychiatr Res 12, 189-198.

[58] Lindeboom J, Schmand B, Tulner L, Walstra G, Jonker C (2002) Visual association test to detect early dementia of the Alzheimer type. J Neurol Neurosurg Psychiatry 73, 126-33.

[59] Shulman KI (2000) Clock-drawing: Is it the ideal cognitive screening test? Int J Geriatr Psychiatry 15, 548-561.

[60] Farid K, Charidimou A, Baron JC (2017) Amyloid positron emission tomography in sporadic cerebral amyloid angiopathy: a systematic critical update. Neuroimage Clin 15, 247-263.

[61] MacDonald SWS, Hultsch DF, Dixon RA (2011) Aging and the shape of cognitive change before death: terminal decline or terminal drop? J Gerontol B Psychol Sci Soc Sci 66B, 292-301. 